Vera Lúcia F. P. Fernandes ${ }^{1}$

Marcelo Luís R. S. Tavares ${ }^{1}$

28. Ramsay JA, Blinkei C, Garner S, MacDougall JD,

Sale DG (1990) Strength training effects in prepubes-

cent boys. Med Sci Sports Exerc 22: 605-614

29. Schmitbleicher D (1992). Training for Power

Events. In: Komi PV. London: Blackwell Scientific Pu-

blication, 381-396

30. Seabra A, Catela D (1998). Maturação, crescimen-

to físico e prática desportiva em crianças. Revista Ho-

rizonte 14: 15-17

31. Van Praagh E, DoréE (2002). Short-term muscle

power during growth and maturation. Sports Med 32:

701-28

32. Vittori (1990). El entrenamiento de la fuerza para

el Sprint. Tomo IV

33. Wong P, Chamari K, Wisloff U (2010). Effects

of 12-week on-field combined strength and power

training on physical performance among $\mathrm{u}-14$ young

players. J Strength Cond Res 24: 644-652.
Ayra Lovisi Oliveira ${ }^{1}$

Ludmila Nunes Mourão ${ }^{1}$

${ }^{1}$ Faculdade de Educação Física

e Desportos, Universidade Federal de Juíz de Fora, Minas Gerais, Brasil.
RESUMO

\section{A produção de feminilidades}

\section{de atletas de Luta Olímpica}

\section{PALAVRAS CHAVE:}

Luta Olímpica. Mulheres. Feminilidade.

Uma feminilidade hegemônica culturalmente construída atribui a passividade, a delicadeza e a beleza como características essenciais das mulheres. As práticas esportivas constituem-se em elementos influenciadores dessa construção social, sendo que as lutas são identificadas como esportes agressivos, de constituição e exercício da masculinidade e, por isso, desaconselhadas às mulheres. Este estudo teve por objetivo analisar as representações de feminilidade de lutadoras profissionais e perceber até que ponto se aproxima e/ ou afastam da feminilidade hegemônica. Baseado no aporte teórico dos estudos de gênero e metodológico das representações sociais percebeu-se que as atletas constroem feminilidades plurais, combinando características culturalmente masculinas e outras da cultura feminina e, dessa forma, deixam suas marcas neste território ainda hegemonicamente masculino das lutas. Faz-se necessário o aprofundamento das pesquisas no tema para que possamos conhecer as representações de outras lutadoras, a fim de contribuir para a ampliação das discussões sobre a pluralidade das formas de ser e viver feminilidades e, assim, dissolver normatizações culturais que ainda buscam dificultar a presença das mulheres no campo das lutas. 
The production of feminilities

in wrestling athletes

\section{ABSTRACT}

A culturally constructed hegemonic femininity assigns passivity, delicacy and beauty as essential characteristics of women. Sports practices constitute influential elements from this construction, so the fights are identified as aggressive sports, construction and exercise of masculinity and therefore not advised for women. This study aimed to analyze the representations of femininity in professional fighters and realize how the approaches are closer or distant from the hegemonic femininity Based on the theoretical framework of gender studies and methodology of social representations was realized that athletes build plural femininities, combining typically masculine characteristics with feminine and thus these characteristics leave their mark on this territory from the hegemonic masculine struggles. It is necessary to deepen the research on the topic so that we can know the representations of other fighters in order to contribute to broader discussions of the plurality of ways of being and living femininity and thereby dissolving cultural norms that seek to further complicate the presence of women in the field of struggles.

\section{KEY WORDS:}

Wrestling. Women. Feminility.

\section{INTRODUÇÃo}

Os esportes apresentam-se como um dos fenômenos culturais mais significativos da atualidade e por meio destes é possível difundir novos valores, mas também, reafirmar antigas normatizações. Como qualquer outra prática social, é um espaço onde se produz e reproduz representações de masculinidade e feminilidade que são inscritas nos corpos, marcando a pele e os modos de viver de homens e mulheres ${ }^{(1)}$.

As lutas, que constituem o campo de investigação do presente estudo, por exemplo, foram historicamente definidas como território de reserva masculina; são identificadas como práticas esportivas agressivas, de construção e exercício da masculinidade ${ }^{(5)}$. Ainda assim, há tempos as mulheres estão adentrando esse território e construindo distintas formas de ser e estar neste espaço ainda não consensual sobre sua presença.

A categoria analítica gênero recusa a ideia de que o sexo anatômico é determinante na imposição das diferenças entre homens e mulheres, mas sim, que essas identidades são construídas social e culturalmente. 0 gênero, de um modo geral, é percebido como identidade-chave para a construção da significação dos sujeitos e fator determinante para sua qualificação dentro de uma determinada sociedade. Já a nomeação do sexo restringe a construção e percepção da corporeidade do sujeito, categorizando modelos de ser masculino e de ser feminino, descartando qualquer possibilidade de articulação com as pluralidades ${ }^{(4)}$.

Os estudos de gênero, a partir de meados da década de 1970 nos Estados Unidos e Europa e dos anos de 1980 no Brasil, inicialmente, propunham pesquisas que buscassem visibilizar as mulheres como sujeitos da própria história. Mais recentemente, foi introduzida a perspectiva de que o esporte é uma prática social sexuada, uma vez que homens e mulheres o praticam, mas também, generificada e generificadora, constituindo-se como um importante espaço para estudos sobre a construção e incorporação de masculinidades e feminilidades (11).

No Brasil, uma lei ${ }^{1}$ proibiu a participação de mulheres em determinadas práticas consideradas "violentas a natureza de seu sexo", inclusive as "lutas de qualquer natureza", em meados do século passado. Nos dias de hoje, uma série de dispositivos ainda busca manter as mulheres afastadas das lutas, a fim de construírem sujeitos femininos adequados à norma.

Nesse sentido, observamos que "o comportamento normal das pessoas em nossa sociedade (e provavelmente em qualquer sociedade) pode ser visto como uma série de compromissos progressivamente crescentes, com normas e instituições convencionais" (3: 39),

1- 0 Decreto-lei 3199/41, que entrou em vigor no dia 14 de abril de 1941, dizia em seu Art 54 do Cap-

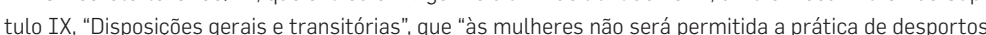
tulo IX, "Disposçoss gorilo instruçāes às entidades desportivas do pa's"'. E em 1965, através da Deliberacão $7 / 65,0$ CND criou a regra que diziza às mutheres - item 2: nã seria permitida a prática "de lutas de quer notou futebol. futebol de salão, futebol de praia, polo, rughy, halterofilismo beisebol" Decisāo esta ruvogad somente em dezembro de 1979. Fonte: Mourão, (1998) Representaçã social da mulhe brestevas atividades físico-desportivas: da segregacăoa à democratização. Rio de Janeiro: UGF. 
e aqueles que a estes transgride são considerados desviantes. Entretanto, as regras e os rótulos são construídos socialmente em meio a processos políticos, nos quais alguns grupos conseguem impor seus pontos de vista como mais legítimos que outros. Ou seja, o desvio reside na representação do outro que a este reage.

No que diz respeito às mulheres, o normal é que elas vivenciem o espetáculo esportivo "desde que não deixe de lado a beleza e a graciosidade, atributos colados a uma suposta 'essência feminina" (9: 02). Pelo contrário, a elas são incentivadas práticas esportivas e corporais que busquem, senão potencializar, pelo menos, evidenciar essa feminilidade hegemônica que, somada à beleza e graciosidade, também the confira gestualidades e comportamentos mais passivos. Por isso, é um equívoco acreditar na passividade como um dado biológico das mulheres. De outra forma, é fruto da educação destinada às meninas pela sociedade. No entanto, algumas mulheres indiferentes às convenções sociais se sentem seduzidas e desafiadas a aderirem à prática das modalidades consideradas masculinas, seguindo carreira como lutadoras. São mulheres que possuem "algo" em sua personalidade que não se consegue explicar, mas as atrai para esse território ainda tão marcado pela hegemonia masculina (6).

Nesse sentido, o presente estudo tem por objetivo analisar as representações de feminilidades de lutadoras profissionais da modalidade Luta Olímpica (LO) no estilo livre, a fim de compreender até que ponto suas representações se aproximam e/ ou se distanciam daquela feminilidade hegemônica. A escolha pela modalidade se deve à intenção de aumentar a visibilidade da LO, em especial no estilo livre, cujos resultados esportivos positivos das lutadoras brasileiras vêm demonstrar o trabalho árduo desenvolvido pela equipe técnica, assim como pelas atletas ${ }^{2}$.

\section{MATERIAIS E MÉTODOS}

O estudo ${ }^{3}$ contempla uma abordagem qualitativa ${ }^{(2)}$ do tipo descritivo e encontra sua fundamentação teórica nos Estudos de Gênero. Seu corpus empírico se estrutura a partir da realização de entrevistas com três atletas da seleção brasileira de LO.

As entrevistas foram gravadas, transcritas e trazem questões relacionadas à história de vida das atletas, inserção e permanência no esporte. No entanto, considerando os objetivos desse estudo, focalizamos nossa análise em duas perguntas norteadoras: "Você acha que as exigências técnicas e corporais ${ }^{4}$ da LO interferem na sua feminilidade?" e "Para você, o que é ser feminina?"

2 - Para mais, acessar: <cbla.com.br>. Acesso em: 23/jan./2014

3 - Este estudo é parte de uma pesquisa de mestrado, cujo projeto foi aprovado pelo Comitê de Ética Pesquisas com Seres Humanos (CEP/UFJF) Sob o número 190.069.

4 - Chamamos de exigências técnicas e corporais das lutas o treinamento técnico e físico que, normalmente, resultam em fortalecimento e desenvolvimento muscular, demonstracọoes de força, agressivida de e virilidade nos treinos e competiçöes.
As representações sociais nos auxiliaram a compreender as questões investigadas na medida em que são caracterizadas como uma maneira de interpretar e de pensar a realidade, e como uma forma de conhecimento elaborada no social, de modo que também cumpre a função de fixar a posição dos sujeitos e grupos com relação a situações, eventos, objetos e comunicação que thes concernem. Ou seja, o seu interesse é compreender o que as pessoas pensam sobre determinados objetos e, principalmente, como se comunicam a respeito deste objeto na cultura, apresentando ideias comuns ou diferenciadas de acordo com a sua imersão em sistemas distintos de valores ${ }^{\left({ }^{14)} \text {. }\right.}$

A representação de um objeto corresponde ao conjunto de informações, crenças e opiniões acerca dele, e as opiniões são fruto das experiências individuais e das trocas e interações sociais. Dessa forma, os elementos presentes nas narrativas das entrevistas coletadas para o estudo possuem importante valor, na medida em que participam do núcleo de representação que as atletas estabelecem com o objeto investigado.

\section{RESULTADOS}

Se, no campo das representações sociais, as práticas esportivas podem influenciar de forma positiva ou negativa nas construções de masculinidades e feminilidades buscando, de forma a manter homens e mulheres nos limiares generificados, o que dizem as lutadoras profissionais, uma vez que são mulheres que ousaram ao convencional, ultrapassando as fronteiras do gênero? Dessa forma, ao serem questionadas se as exigências técnicas e corporais da LO influenciam em sua feminilidade, A, A2 e A3 assim responderam, conforme quadro abaixo:

\section{1 - INFLUÊNCIA DA LO NA FEMINILIDADE DAS ATLETAS}

"Ah, no momento do treino, ali em cima do tapete, na luta, interfere sim porque eu não posso ter o meu cabelo do jeito que eu quero, eu tenho que prender ele todo, senão pode me atrapalhar. Então, al o mequ

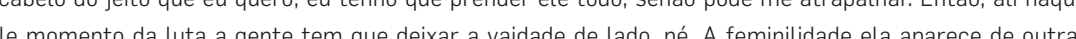

A1 maneiras, eu posso pintar a minha unha, eu posso fazer outras coisas, mas, ela é limitada, né. [...] Não dá pra ter unha grande, não dá pra ficar passando hidratante senão a gente sua e escorrega pra treinar. [.. Agora fora do treino, fora da competição não vai mudar em nada, não vai atrapalhar em nada. [...] Eu volto à menininha de novo.

É sempre mais difícil no começo quando você vê as mudanças, porque quando eu comecei a entrar na luta olimpica euvi que eu tava ficando musculosa, você começa a se assustar, né Mas depois é normat. [. ] A2 depois que eu saio dali do tapete eu sou uma mulher. Ali dentro eu continuo sendo mulher, mas eu sei que dentro eu tenho que agir com outros tipos de... outras grosserias, com outras coisas [...] Sei que eu tenho que ser forte, porque senão não dá. Não posso competir com as melhores do mundo como uma lady, uma mocinha. Não, eu tenho que ter garra de mulher forte. Então, eu vejo isso como uma coisa normal." 
"Às vezes, às vezes. Não dá pra mentir que não. Por exemplo, eu adoro unha comprida, eu queria ter a minha unha longa e não dá, não posso, porque senão eu vou arranhar todo mundo no treino [...]. Cabelo, às vezes,

A3 acaba quebrando um pouco. [...] Eu tenho que lutar até 72. Eu acho que eu fico muito magra com 72, mas eu tenho que ter esse peso, paciência. [...] Eu acho que dá para manter a feminidade lutando. Então, eu não desisto, sabe. Eu tento ser feminina o tempo todo."

FONTE: ELABORAÇÃO PRÓPRIA

E a fim de tentamos delimitar melhor o que entendiam pelo marcador identitário da feminilidade mostrou-se pertinente perguntarmos de bastante direta: o que é ser feminina?

2 - REPRESENTAÇÃO DAS ATLETAS SOBRE O QUE É SER FEMININA

A1 "Muitos pensam que a feminina é só aquela fresquinha, aquela mulher cheio de frescura. A outra brava também pode ser feminina".

"Ah, eu acho que é ser sensivel, claro, sabe, tipo... É ser, é continuar sendo mulher, tipo assim, nos momentos que tem que ser. Por exemplo, quando eu tenho que chorar eu choro. Quando eu tenho que ser sensível eu sou

A2 sensível. Então, eu acho que ser feminina é ser feminina na ocasião certa. É ser feminina sempre. Na hora que você tem que fazer aquilo, você faz aquilo. Você vai se adaptando aos momentos certos, às situaç̄es certas, mas sem deixar de ser feminina. Acho que ser mulher é isso. Éme adaptar a todas as situações sendo eu mesma."

"É a gente aceitar que, apesar de toda a nossa garra pra lutar, a gente tem nossas fraquezas, é saber tirar A3 proveito delas. Eu acho que mesmo lutando eu não preciso ser forte o tempo todo, eu posso ser maliciosa, eu posso ser jeitosa e usar da minha feminilidade pra ganhar:

FONTE: ELABORAÇ̄̃o PRÓPRIA

\section{DISCUSSÃO}

Diante dos resultados, é possível perceber entre as participantes deste estudo três principais aspectos relevantes: a) os distintos modos e níveis de influência da LO na constituição de suas feminilidades; b) o quão conflituoso pode ser adequar a identificação com a profissão de lutadora às próprias representações de feminilidade; c) e ainda, o quanto o corpo se manifesta nestas representações. Nessa perspectiva, notamos que a lutadora A1 não encara como um problema a manifestação "limitada" da sua feminilidade no tapete 5, diferentemente de A3. E que, enquanto A1 e A2 buscam distinguir suas identificações dentro e fora da LO, A3 procura evidenciar uma manifestação única de sua feminilidade e dentro do ideal dominante. Contudo, percebemos que tais representações apresentam-se mescladas ou, em outras palavras, se manifestam de formas plurais.

5 - Tapete olímpico é nome dado à área de confrontos das disputas de LO
Nos dias de hoje é ingênuo que ainda seja falado "da feminilidade, do feminino ou da mulher como se houvesse alguma essência ou uma forma singular de viver essa condição" (13:s/p). De forma contrária, não há uma fixidez na constituição dessas identidades, uma vez que são produzidas na cultura. As múltiplas experiências e influências étnicas, religiosas, de classe, de gênero e outras constroem uma diversidade de possibilidades, cujo enfrentamento ou os modos de subordinação a essas circunstâncias também são múltiplos ${ }^{(10)}$.

A1, de forma amena, busca evidenciar em sua fala que quando a lutadora entra em cena procura se concentrar no treino ou confronto, desligando-se de preocupações com a aparência, mas que, apesar disso, não deixa de marcar a presença de signos culturalmente femininos no tapete. As unhas pintadas, reveladas em sua narrativa, aparecem como uma característica da vaidade feminina que transita dentro e fora dos treinos e lutas. Tal artefato cultural parece se caracterizar como uma das maiores expressões da feminilidade hegemônica entre lutadoras no exercício da profissão.

Dentro da perspectiva das subjetividades - atitudes, gestualidades e comportamentos - percebemos que A2 aponta para a sensibilidade, a delicadeza e a passividade como características das mulheres na qual, embora possam se manifestar nos "momentos certos", considera não haver espaço para estas no tapete. De outra forma, afirma é que preciso deixar esses elementos de fora e incorporar outros culturalmente masculinos, como a força e algumas "grosserias" para entrar em cena a mulher guerreira.

Essa ideia de oposição entre a "mulher" e a "guerreira" é fruto do binômio masculino/ feminino socialmente construído que, historicamente, atribui esse ethos ${ }^{6}$ guerreiro a uma "natureza dos homens" e está fortemente afirmado entre os lutadores, muito mais do que em qualquer outro esporte ${ }^{(5)}$. Além disso, a perspectiva de A2 sobre a subjetivação do masculino no tapete pode ser apreendida através do observado em outros estudos, que dizem sobre o ambiente das academias de esportes de combate e artes marciais em geral ser dominado por um tipo de cultura masculina impregnada pela "semântica da virilidade que considera a presença feminina uma afronta à ordenação simbólica daquele universo" (16).

Noutra perspectiva, observarmos no relato de A3 a recusa em incorporar estas características atribuídas ao masculino em sua constituição como atleta. Este fato parece vir como um modo de dizer que as mulheres não precisam se "masculinizar" para construírem uma carreira como lutadoras. Ou ainda, que o fato de ser lutadora em nada vai atrapathar o seu desempenho como mulher/ feminino.

Dessa forma, de acordo com as narrativas das lutadoras, na perspectiva das subjetividades é possível uma "escolha" entre o incorporar ou não a agressividade e a delicadeza, por exemplo, sendo que o corpo já não responde da mesma forma. Em A3 percebemos o

- No dicionário de língua portuguesa, ethos é um termo antropológico que significa: característica comum a um grupo de indivíduos pertencentes a uma mesma sociedade. Disponivel em: <http://www. dicionariodoaurelio.com/dicionario.php?P=Ethos>. Acesso em: 10/jan./ 2014. 
quanto a atleta gostaria de poder conciliar os aspectos que julga importantes de sua feminilidade a sua condição de lutadora. Dentre estes, destacamos a questão do peso corporal, em que afirma se sentir magra demais por ter que manter-se até os $72 \mathrm{~kg}$, demostrando um conflito entre a sua representação de feminilidade e sua condição de lutadora.

A categoria até $72 \mathrm{~kg}$ era, até dezembro de 2013 , a mais "pesada" do feminino, enquanto que no masculino podiam competir em categorias até $120 \mathrm{~kg}$, ambos no estilo livre. Esse aspecto nos remete a concepções históricas em que a mulher acima de certo limite de peso, força e/ou desenvolvimento muscular coloca em risco aquela representação ideal de feminilidade ${ }^{(12)}$. Entretanto, percebemos que a lutadora gostaria de subir um pouco seu peso, não sob a perspectiva da constituição de novas formas de feminilidade, mas, para afirmar uma representação hegemônica, na qual entende que seu peso, este regulado pela condição de atleta de LO, poderia ser mais proporcional à sua altura.

Contudo, A3 demonstra que aprendeu a aceitar seu corpo de lutadora com o passar do tempo, embora não se sinta plenamente satisfeita ou segura às mudanças ocasionadas desde a sua inserção nas lutas. Uma coincidência, é que sua categoria foi reajustada para até $75 \mathrm{~kg}$ após a reformulação das regras da LO pela Federação Internacional de Lutas Associadas (FILA), em dezembro de $2013^{7}$. É possível que com este ajuste a relação entre a altura e o peso corporal se mostre mais adequado ao que a lutadora considera ideal para si

Em A2, observamos que o evidente desenvolvimento muscular assustou a atleta no início da carreira. Esse fato poderia ser percebido também como um conflito, na medida em que se mostra comum que para serem aceitas nos locais de treino elas precisam igualarse aos homens, ao mesmo tempo em que devem preservar uma aparência que os outros julguem como feminina ${ }^{\left({ }^{6}\right)}$. No entanto, percebemos que $\mathrm{A} 2$ se adaptou às mudanças corporais adquiridas com os anos de dedicação à LO e hoje vê como uma "coisa normal". A atleta acredita que para constituir-se como lutadora a força física é um importante elemento, e este inevitavelmente transparece no corpo.

Algumas lutadoras tendem a considerar o desenvolvimento muscular como uma masculinização de seus corpos. A respeito disso, uma lutadora de Mixed Martial Arts (MMA) profissional, que possui aparência musculosa, diz que “'a masculinização do corpo é inevitável', devido à carga muito intensa de treino" (15: 17). Essa perspectiva diz sobre o corpo feminino que quando excessivamente transformado pelo exercício físico e/ou pelo treinamento contínuo lhes são atribuídas características viris que podem questionar a beleza e feminilidade da mulher ${ }^{(3)}$.

Estas representações vão ao encontro dos setores mais conservadores da sociedade brasileira que se sentem incomodados quando o ideal de feminilidade, marcado pela delicadeza na aparência e nos gestos, é tensionado por certas características comuns do uni-

7 - Fonte: <http://cbla.com.br/2013/12/17/fila-divulga-novas-categorias-de-peso/>. Acesso em: 23/ian./2014 verso da cultura física. Elementos como o suor excessivo, esforço físico, emoções fortes, competições, rivalidade consentida, músculos delineados, ousadia de caráter, perigos das lesões, além de leveza das roupas e seminudez, revelam-se incompatíveis a uma representação de feminilidade normatizada ${ }^{(8)}$

Diante disso, é comum entre atletas que possuem a estrutura muscular desenvolvida o investimento acentuado na aparência, como acontece à lutadora de MMA supracitada e não parece se configurar numa preocupação exacerbada entre as lutadoras deste estudo. Percebemos que para essas mulheres a condição de atleta fala mais alto, na medida em que mantêm seus corpos à disposição do esporte, revelando que não se trata de abrir mão de vontades pessoais, mas sim, de assumir suas escolhas pela profissão de lutadora ${ }^{(6)}$.

Mesmo em A1, compreendemos através da "menininha" que se manifesta em seu cotidiano fora das lutas uma referência ao uso daquilo que não é possível levar para o tapete, como o cabelo solto e hidratante corporal, e não uma preocupação em esconder ou disfarçar o seu "corpo de lutadora". A atleta incluindo-se num arquétipo de mulher "brava" que se cuida, sim, mas sem preocupações com exageros, e manifesta uma feminilidade marcada por atitudes mais ativas e intensas dentro e fora do tapete.

Diante do exposto, podemos perceber que, apesar de apresentarem em comum o envolvimento com a $\mathrm{LO}$, as atletas possuem em suas representações aspectos semelhantes, mas também outros bastante distintos, não sendo possível falar em "uma representação de feminilidade de lutadoras". Isso confirma a perspectiva das teorias feministas as quais dizem que as formas de ser e viver feminilidades são plurais ${ }^{(11 ; 13)}$. E ratifica a expectativa da teoria das representações sociais, uma vez que o meio, mas também as opiniões e crenças individuais participam da construção e representação de um objeto ${ }^{(14)}$, neste caso, da representação de feminilidades. Os resultados demonstram que uma das formas de entender a feminilidade é através de uma representação hegemônica marcada pela delicadeza, malícia e um corpo proporcional, mas também, como uma construção que aceita as influências do meio, neste caso, da LO, revelando corpos fortes e atitudes mais ativas. As atletas incorporam certas gestualidades e comportamentos considerados masculinos como forma de pertencimento ao ambiente em que estão envolvidas. Contudo, também investem em cuidados tipicamente femininos a fim de exteriorizar que esses investimentos em nada interferem sobre seu desempenho profissional. As atletas registram sua presença neste território ainda marcado pela hegemonia masculina e descentram a ideia de que ser lutadora afeta seus modos de ser feminina e, assim, constroem novas representações de feminilidades mais plurais. Apontamos para a necessidade de aprofundamento das pesquisas no tema para que possamos conhecer as representações de outras lutadoras, a fim de contribuir para a ampliação das discussões sobre a pluralidade das formas de ser e viver feminilidades e, assim, dissolver normatizações culturais que ainda buscam dificultar a presença das mulheres no campo das lutas. 


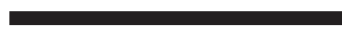

1. Adelman, M. (2007). Mulheres no Esporte: Corporalidades e Subjetividades. In: Movimento, Porto Alegre,

v. 12, n. 1, p. 11-29.

2. Bauer, M. W. Gaskell, G. Pesquisa qualitativa com texto, imagem e som: um manual prático. Petrópolis: Vozes, 2002
15. Moura, DL; Bento, GS; Santos, FO; Lovisolo, H. 2010). Esporte, Mulheres e Masculinidades. In: Es-

16. Thomazini, SO, Moraes, CEA \& Almeida, FQ. (2008). Controle de Si, Dor e a Representação Feminina entre Lutadores(as) de Mixed Martial Arts. In: Pensar Prática, vol.11, no. 3, p. 281-290. porte e Sociedade, ano 5, n 13, p. 1-22.

3. Becker, HS (2009). Outsiders: Estudos de sociologia

do desvio. Tradução: Borges, ML. Rio de Janeiro: Zahar.

4. Butler, J. (2010). Problemas de gênero: feminismo e subversão da identidade. Rio de Janeiro: Civilização Brasileira.

5. Elias, N. (Org.) (1992). A busca da excitação. Lisboa: Difel, 1992.

6. Ferretti, MAC (2011) A Formação da Lutadora: estudo sobre mulheres que praticam modalidades de lutas. São Paulo: USP.

7. Goellner, SV (2003). Bela, Feminina e Maternal: imagens da mulher na Revista Educação Physica. Ijứ: Unijuí. 8. Goellner, SV (2005). Mulheres e futebol no Brasil: entre sombras e visibilidades. Rev. bras. Educ. Fís. Esp. São Paulo, v.19, n.2, p. 143-151.

9. Goellner, SV (2007). 0 Esporte e a Cultura Fitness como Espaços de Generificação dos Corpos. Anais do XV Congresso Brasileiro de Ciências do Esporte, 16 a 21 de setembro, Recife, p. 1-9.

10. Goellner, SV (2010). A educação dos corpos, dos gêneros e das sexualidades e o reconhecimento da diversidade. In: Cadernos de Formação RBCE, vol.1, no. 2, p.71-83.

11. Goellner, SV (2013). Gênero e esporte na historiografia brasileira: balanços e potencialidades. In: Revista Tempo, vol.17, no. 34, p. 45-52.

2. Goellner, SV; Fraga, AB. (2003) Antinoüs e Sandwina: encontros e desencontros na educação dos corpos brasileiros. Movimento, Porto Alegre, v. 9, n. 3, p. 59-82. 13. Louro, GL (2008). Feminilidades e Pós-modernidade. In: MOTA, L. Invencãa do Contemporâneo: a construção dos gêneros (vídeo). Disponível em: http://vimeo.com/28127159. Acesso em: 14 de maio de 2013.

14. Moscovici, S (2007). Representações Sociais: investigações em psicologia social. Petrópolis: Vozes. do São Francisco, Brasi

\section{RESUMO}

AUTORES:

Edmilson S. dos Santos

A participação

na difusão do Programa

GEPPOL Universidade Federatovile

\section{Segundo Tempo/ ME}

PALAVRAS CHAVE:

Políticas públicas. Esporte educacional.

Implementação.

Este estudo busca analisar a participação dos governos estaduais na difusão do Programa Segundo Tempo do Ministério do Esporte no intervalo de 10 anos (2003 a 2012). Os incentivos à descentralização do programa não foram suficientes para garantir maior participação dos governos estaduais em sua difusão. Após dez anos não foi possível capturar uma cultura institucional que permita garantir efeitos redistributivos e consequente diminuição das desigualdades regionais de acesso ao esporte educacional. 